junior staff to achieve a safety net on the current number of sites. On the basis of a one in three rota maintained with locums, 19 sites could be staffed according to safety net criteria, seven fewer than currently, and only if $19 \%$ of the senior house officers had at least 12 months' paediatric experience. On the basis of a one in three rota maintained internally 12 sites could be staffed, 14 fewer than currently, and only if $28 \%$ of the senior house officers had at least 12 months' paediatric experience.

We agree wholeheartedly with the views of $\mathrm{Dr}$ Jones and colleagues that radical changes are urgently needed to address the proper delivery of paediatric health care. It is clear to us that to provide a safe and efficient service for children and to train junior staff appropriately there must be a move to fewer children's departments. This is a proposal supported by the British Paediatric Association in its response to the draft consultative document Welfare of Children in Hospital. ${ }^{2}$ Even if a reasonable level of centralisation is achieved, if we are to meet all the constraints currently facing us there may be insufficient staff to provide a safe level of care. These considerations also apply to a lesser extent to a number of other specialties. In common with our colleagues in North East Thames we also believe that the time has indeed come to modify the proposals in Plan for Action.

ALASTAIR SCOTLAND SHEILA MCKENZIE

North East Thames Regional Health Authority,

London W/2 3QR

1 Jones SAM, Kovar I, Williams M, Bentley D. Is it possible to "achieve a balance" and meet the "safety net"? Br Med $\mathcal{F}$ 1989;299:841-3. (30 September.)

2 British Paediatric Association. Comments on draft circular, August 1988. Welfare of Children in Hospital. London: BPA, 1989.

\section{Application of airline pilots' hours to junior doctors}

SIR,-Having read the article by Drs A Murray Wilson and G Weston' ${ }^{1}$ and the resultant correspondence, ${ }^{2}$ we would not wish to enter a controversy based on the "stress quotient" comparison between junior doctors and pilots. We believe that such a controversy would ultimately not be helpful in solving the very real problems of either profession, although there are clearly some factors that are relevant to both; nor can we accept Mr David R McCoy's inference that the degree of stress suffered can in any way be based on the number of clients or patients routinely at risk on any one occasion.

The Association of Anaesthetists of Great Britain and Ireland has for many years wrestled with this problem and has recently, with the cooperation of its large and active junior group, initiated an investigation under the direction of $\mathrm{Ms}$ Jenny Firth-Cozens and based on her article on emotional distress in junior house officers. ${ }^{3}$ The council of the association has published a booklet that contains a section (para 9.1) devoted to the relation of stress to fatigue. It is perhaps relevant to quote one paragraph from this section:

It is commonly accepted that overwork is an important contributory cause of stress in doctors in training. The practice of medicine in general is too unpredictable, and the specialty of anaesthesia too immediate, to warrant the formulation of strict rules of clinical conduct; thus it is not possible to apply the rigid regulations applicable to, for example, aircraft pilots directly to practising anaesthetists.

By whatever route the fatigue problem is alleviated, reorganisation within some departments and increased funding for manpower seem to be inevitable.

P J HELLIWELL M P COPLANS Association of Anaesthetists of Great Britain and Ireland London WC1B 3RA
Wilson AM, Weston G. Application of airline pilots' hours to junior doctors. BrMed f 1989;299:779-81. (23 September.) McCoy DR. Application of airline pilots' hours to junior doctors. Br Med F 1989;299:974. (14 October.)

Firth-Cozens J. Emotional distress in junior house officers. $\mathrm{Br}$ Med f 1987;295:533-5.

Association of Anaesthetists of Great Britain and Ireland. Consultant:trainee relationships. London: Association of Anaesthetists, 1989.

\section{Sponsored training for overseas doctors}

SIR, - I am grateful to Drs Ricardo Araya and Anthony Pelosi for publicising concerns about the training of overseas doctors that have much exercised those of us responsible for setting up and administering the colleges' double sponsorship schemes.' I should like to assure them that every effort is being made to avoid the potential pitfalls that they outline, though human frailty being what it is I fear that no complex system can be made entirely failure proof.

None the less the following safeguards exist. Consultants and tutors are asked to consider appropriate academic, as well as clinical, training for the placements of "visiting" senior house officers and registrars, and dedicated courses are being run for the trainees in psychiatry. We seek exemption from the Professional Language Assess ment Board examination only for those applicants to our scheme whose overseas sponsor, a psychia trist of some standing, has assured us of the applicant's competency in English.

We are taking every precaution to ensure that candidates of high calibre are sponsored. Forma continuing evaluation will occur every six month (as it does for British trainees), and if it is unsatisfactory the colleges' sponsorship will be withdrawn, thereby immediately ending the doctor's contract

I hope these points offer some reassurance, but would welcome continuing public debate as the schemes develop. We have a responsibilityto young doctors from overseas and for the international reputation of British medicine - to succeed.

Royal College of Psychiatrists

FIONA CALDICOTT

London SWIX 8PG

Arava R, Pelosi A. Sponsored training for overseas doctors. Br Med f 1989;299:980. (14 October.)

\section{Sweating it out}

SIR, - I was interested by Bernard Dixon's exposition of the suggestion by Greenwood and Kwiatkowski that, although the host circadian rhythm may augment the synchrony of Plasmodium spp in man, it is mainly mediated by the fever. ${ }^{1}$ There seem to be four possible factors deciding, or reinforcing, the periodicity of malarial infections the organism's intrinsic programme; the circadian rhythm of the host; specific immunological responses to successive broods with different antigens (as in Trypanosoma brucei); and, as now suggested, the fever. It is informative to study the fever thesis in plasmodial infections in which one of these factors, the circadian rhythm of the host, can be unquestionably ruled out - that is, those in which the periodicity is not a whole multiple of 24 hours.

Shortly before the outbreak of the second world war a stock of the fowl malaria organism, Plasmodium gallinaceum, was brought to the Liverpool School of Tropical Medicine. When war was declared and supplies of drugs from Germany ended, the problem arose of assessing the gametocidal activity of the French drug Praequine as a replacement for the German drug Plasmoquine (Plasmochin). Although the two drugs were thought to be identical chemically, it was essential to confirm experimentally that their gametocidal activities were also equivalent. The late Professor Douglas Bertram and I studied the course of $P$ gallinaceum infections in domestic fowls and compared the activity of the two drugs on the gametocytes, using oocyst counts in mosquitos fed upon the fowls as an index of gametocyte viability. ${ }^{23}$

We accepted at the time that the organism had a definite inherent 36 hour rhythm. Maximum schizogony, as defined by the peaks in the curve for the percentage of schizonts in blood films, was always at 36 hour intervals. Two infections induced by "identical" inocula of blood containing parasites both produced infections with clearly defined 36 hour periodicities, though one was 24 hours out of step with the other. The 36 hour periodicity was also clear in fowls infected by mosquito bite. In all 12 fowls maximum schizogony occurred every 36 hours and the schizogony cycles, defined as soon as the infection was sufficiently developed for this to be done by microscopy, were synchronous. In 11 of the 12 maximum schizogony fell at midnight between days 11 and 12 ; in the remaining one it was at midday on day 13: later in its appearance but in step with the 11 others

We did not measure the temperatures of the birds. I do not know the duration of the preerythrocytic stage of $P$ gallinaceum in fowls. But in 16 intravenous inoculations of massive numbers of organisms the mean prepatent period was 2.75 days, so that the first patency of parasitaemia in fowls infected by mosquitos on days 9-10 might have been only one or two cycles after the rupture of the pre-erythrocytic schizonts; and so the periodicity might have then been mediated by the cycles of fever caused by the parasitaemia.

Oocyst counts in mosquitos fed on the fowls reached the maximum about 24 hours after each maximum schizogony, indicating that gametocytes were produced in successive broods, each brood reaching its highest infective potential for the mosquito after that interval and then being destroyed. This 36 hour periodicity may be of adaptive advantage to the organism by making use for transmission of both of the two peak biting periods of mosquito species that are active in both crepuscular periods, 12 hours apart. ${ }^{+}$But I found that the peak periods of infectivity to mosquitos were related to midday and midnight, not to dusk and dawn. So, I am still puzzled why the periodicity of $P$ gallinaceum should be 36 hours.

Edinburgh EH10 5AX

W H R LUMSDEN

Dixon B. Sweating it out. Br Med f 1989;299:866. (30 September.

2 Lumsden WHR, Bertram DS. Observations on the biology of Plasmodium gallinaceum Brumpt 1935, in the domestic fowl, with special reference to the production of gametocytes and their development in Aedes aegypti (L.). Ann Trop Med Parasitol 1940;34:135-60.

3 Lumsden WHR, Bertram DS. The effect of Plasmoquine and of Praequine on the subsequent development of the gametocytes of Plasmodium gallinaceum Brumpt, 1935, in Aedes aegypti (L.). Ann Trop Med Parasitol 1940;34:161-72.

4 Bertram DS. Discussion [following Hawking F, Worms MJ, Gammage K. 24- and 48-hour cycles of malaria parasites in the blood; their purpose, production and control]. Trans $R$ Soc Trop Med Hyg 1968:62:762-3.

\section{Correction}

Changes in glucose tolerance after treatment for acromegaly

A printer's error occurred in this letter by Dr J A McKnight and colleagues (4 November, p 1162). The last sentence of the first paragraph should have read "In addition, in all three of their cases when growth hormone was lowered by further treatment the severity of the diabetes decreased [not increased] noticeably." 